\title{
Cavernous Sinus Thrombosis in COVID-19 Associated Rhino-Orbital Mucormycosis: A Retrospective Audit in the First Wave of the Pandemic
}

\section{Stuti Chowdhary ( $\sim$ stuti.9894@gmail.com )}

Jawaharlal Institute of Postgraduate Medical Education and Research https://orcid.org/0000-0003-

2154-6400

\section{Arun Alexander}

Jawaharlal Institute of Postgraduate Medical Education and Research

\section{Sivaraman Ganesan}

Jawaharlal Institute of Postgraduate Medical Education and Research Joe Vimal Raj Jawaharlal Institute of Postgraduate Medical Education and Research

Sunitha Vellathussery Chakkalakkoombil Jawaharlal Institute of Postgraduate Medical Education and Research Jijitha Lakshmanan Jawaharlal Institute of Postgraduate Medical Education and Research

\section{Sabharisan Paramasivam} Jawaharlal Institute of Postgraduate Medical Education and Research

\section{Kalaiarasi Raja}

Jawaharlal Institute of Postgraduate Medical Education and Research

\section{Lokesh Kumar Penubarthi}

Jawaharlal Institute of Postgraduate Medical Education and Research

\section{Sunil Kumar Saxena}

Jawaharlal Institute of Postgraduate Medical Education and Research

\section{Research Article}

Keywords: cavernous sinus thrombosis (CST)< COVID-19, rhino-orbital mucormycosis

Posted Date: July 12th, 2021

DOI: https://doi.org/10.21203/rs.3.rs-693804/v1 
License: (c) (i) This work is licensed under a Creative Commons Attribution 4.0 International License. Read Full License 


\section{Abstract}

Purpose Cavernous sinus thrombosis (CST) is a complication of rhino-orbital-cerebral mucormycosis. The COVID-19 pandemic saw a rapid surge in the cases of acute fungal sinusitis, many of whom also had CST, further contributing to the ophthalmoplegia. This study was a retrospective audit of patients with mucormycosis treated during the first wave of the COVID-19 pandemic.

Methods This study was conducted at a tertiary referral centre, and patients with rhino-orbital mucormycosis were included. Relevant laboratory investigations and CT scans of the paranasal sinuses and the cavernous sinus were analysed. Mortality at discharge was calculated.

Results 61 cases of invasive mucormycosis were seen, of whom 20 were COVID-19 positive, and 21 had radiological evidence of CST. All patients in the study initially presented with clinical suspicion of mucormycosis, and COVID-19 was diagnosed during pre-admission investigations. $93 \%$ of patients had diabetes. A majority of patients received Amphotericin B and surgical debridement. The sphenoid sinus was involved in $32(52 \%)$ patients and the orbit in $34(56 \%)$. Factors affecting CST, such as platelet counts, were studied. Fifteen (25\%) patients succumbed during their treatment.

Conclusions $34.4 \%$ of patients with mucormycosis developed CST. Being COVID-19 positive led to an increase in mortality; however, there was no significant increase in death due to simultaneous COVID-19 and CST. Sinus involvement was not significant for the development of CST.

\section{Introduction}

Invasive rhino-orbital mucormycosis is an aggressive and potentially fatal fungal infection seen in the immunocompromised. The ongoing COVID-19 pandemic has caused a sudden spike in cases of COVID19 associated mucormycosis (CAM), mainly from developing nations. This rise of CAM has also uncovered a rise in the clinical entity of cavernous sinus thrombosis (CST), which is a well-known complication of rhino-orbital-cerebral mucormycosis (ROCM). COVID-19 associated hypercoagulable states, hyperferritinemia, diabetic ketoacidosis, and cytokine storms have been proposed for the altered biochemical environment, predisposing to pulmonary embolism, cerebral venous thrombosis, and other manifestations of COVID-19 coagulopathy [1]. Several studies of cerebral sinovenous thrombosis (CSVT) at multiple sites have been diagnosed in patients of COVID-19 co-infection, including sagittal sinus, transverse sinus, and even the sigmoid sinuses, but data on cavernous sinus thrombosis (CST) is scarce.

Before the emergence of COVID-19, the proportions of CST in mucormycosis with diabetics was 11\% [2]. An otherwise rare fungal infection, the increase in CAM cases has predisposed patients to multiple presentations of invasive fungal disease. In association with CAM, cavernous sinus thrombosis has only been reported as isolated case studies [3] [4]. However, no studies have studied the risk factors and outcomes in cavernous sinus thrombosis in CAM. Significant mortality is associated with CST; hence the study of CST and the associated risk factors, particularly in the background of CAM, assumes importance for optimal patient management. 
In addition to the treatment of invasive fungal sinusitis, including reversing immunosuppression, rapid reduction of fungal load, and intravenous Amphotericin B, the urgent need to recognise and treat CST in this setting probably contributes to survival. This study is a retrospective audit of the clinical management of 61 patients of invasive mucormycosis seen in a tertiary care hospital treating both COVID-19 and non-COVID-19 patients from March 2020 to February 2021, which constituted the 'first wave' of the pandemic. The objectives of this retrospective study were to estimate the proportions of cavernous sinus thrombosis among COVID-19 positive and negative mucormycosis cases and determine mortality in patients with cavernous sinus thrombosis and CAM.

\section{Materials And Methods}

This study was carried out in patients with invasive fungal sinusitis presenting to the otolaryngology department of the institute from March 2020 to February 2021. Institutional Ethics Committee approval (JIP/IEC/2021/084) was obtained to conduct this study. The data of the patients were accessed from the electronic hospital records and digitally archived CT scans. Relevant data about underlying comorbidities, visual acuity, extent of the disease and presence of cavernous sinus thrombosis was collected. The biochemical parameters at presentation and the treatment history were also studied. Proposed risk factors at presentation were also tabulated and analysed. Tissue diagnosis was available for all the patients. Descriptive statistics were used to present the data. The odds ratios, confidence intervals, and significance levels were calculated for the mortality data.

\section{Results}

A total of 61 patients were treated for rhino-orbital mucormycosis within this period. All the patients underwent COVID-19 testing by reverse transcriptase-polymerase chain reaction (RT-PCR), rapid antigen testing (RAT) or were diagnosed by a CT scan of the chest at admission. Out of the 61 patients, 20 were COVID-19 positive at the time of admission. The patients in this study were primarily recruited during the first wave of the pandemic. The clinical diagnosis of mucormycosis was made before that of COVID-19 in all the study subjects. None of the patients had received steroid therapy or anticoagulation before or during their hospital stay.

The mean age of the patients was 50.4 years, with a range of 18 to 75 years. Among the 61 cases, a vast majority were male (Table 1). 57 (93.4\%) patients had diabetes. Among the 57 diabetic patients, 20 (35.08\%) were COVID positive, and 37 (64.9\%) were COVID negative.

The visual acuity of all patients at admission was recorded (Table 1) using a Snellen's chart at admission. Among the 61 cases, seven patients had normal vision, 30 patients had diminished vision, ranging from $6 / 9$ to $6 / 60.4$ patients had only perception of hand movements, while 20 patients had no perception of light. The proportion of these data are distributed as among the COVID positive cases, one (5\%) had normal vision, seven (35\%) had diminished vision, $1(5 \%)$ had hand movements, and $11(55 \%)$ 
had no perception of light. Similarly, among the COVID negative patients, 6 (14.6\%) had normal vision, 23 $(56.1 \%)$ had diminished vision, $3(7.3 \%)$ had hand movements, and $9(22 \%)$ had no perception of light.

Clinical and biochemical parameters of the study subjects are given in Table 1. Serum blood glucose at admission was normal in 13 patients, between $140 \mathrm{mg} / \mathrm{dl}$ and $300 \mathrm{mg} / \mathrm{dl}$ in $28(45.9 \%)$ patients and more than $300 \mathrm{mg} / \mathrm{dl}$ in 20 of the patients. These data are distributed among the COVID positive cases as 2 (10\%) had normal glucose, $8(40 \%)$ had values between $140-300 \mathrm{mg} / \mathrm{dL}, 10(50 \%)$ had random blood glucose above 300 . Similarly, among the COVID negative patients, $11(26.8 \%)$ had normal glucose, 20 (48.8\%) had values between 140-300, and 10 (24.4\%) had random blood glucose above 300.

Patients were treated with systemic liposomal Amphotericin B supplied from the hospital (Table 1). Among the 20 COVID positive cases, 18 had received Amphotericin B, of whom 4 (20\%) had received < $2000 \mathrm{mg}$. Out of the 41 non-COVID cases, $36(87.8 \%)$ had received Amphotericin B, of which $9(22 \%)$ had received suboptimal doses. Thirteen $(N=13 / 54,22.2 \%)$ patients could not be given the targeted cumulative dose of $2000 \mathrm{mg}$ primarily due to poor renal function (Table 1). 3 patients died during the treatment, and 2 patients refused further treatment. Seven patients received no amphotericin, of whom 4 died before any treatment could be started, two patients refused any treatment, and one received Amphotericin B at a second hospital (Table 1).

Surgical debridement was undertaken for a majority $(N=49 / 61,80.3 \%)$ of the patients. The endoscopic approach was performed in $3(15 \%)$ of the COVID positive patients and $20(48.8 \%)$ non-COVID patients. Surgery via the combined approach was done in one (5\%) of the COVID positive and $8(19.5 \%)$ of the COVID negative cases. $3(15 \%)$ of the COVID positive cases and $2(4.9 \%)$ of the COVID negative patients had undergone orbital exenteration. Three patients $(N=3 / 61)$ refused any surgical treatment (Table 1$)$.

Forty-six ( $N=46 / 61,75.4 \%)\{12 / 46=26.08 \%$ COVID positives and 34/46 $=73.9 \%$ COVID negatives $\}$ patients were discharged alive from the hospital on completion of the course of treatment. Fifteen $(\mathrm{N}=$ $15 / 61,24.6 \%)\{8 / 15=53.3 \%$ COVID positive and $7 / 15=46.6 \%$ COVID negative $\}$ patients died during their treatment (Table 1).

Among these 15 patients, cavernous sinus thrombosis was present in $5(\mathrm{~N}=5 / 1533.3 \%)$ patients. The proportion of concurrent cavernous sinus thrombosis and COVID-19 infection was 5 out of which 2 ( $\mathrm{N}=$ $2 / 5,40 \%)$ died. The mortality rate was higher among COVID positive CST $(N=2 / 5,40 \%)$ than those who were non-COVID CST $(\mathrm{N}=3 / 16,18.75 \%)$.

The extent of the disease was diagnosed using a CT scan of the paranasal sinuses (Table 2). Among the 61 patients, cavernous sinus thrombosis was encountered in 21 patients in which 5 (23.8\%) were COVID positive, and $16(76.1 \%)$ were COVID negative. 32 patients had involvement of the orbit in some form: erosion or thinning of the lamina papyracea, extraconal extension, bulky medial rectus, soft tissue at the orbital apex, intraconal spread, proptosis and breach in bony boundaries (Fig. 1, Fig. 2) Only 11 of the 32 (34.3\%) patients with orbital disease had CST. Forty-five ( $N=45 / 61,73.7 \%)$ patients had involvement of the sphenoid sinus and the orbit simultaneously, apart from the involvement of the other sinuses. The 
cavernous sinus was affected in 15 (out of 21 patients, 71.42\%) patients who also had the disease in the sphenoid sinus and orbit.

The hypercoagulable factors like COVID positivity, uncontrolled blood glucose, raised platelet counts hypothesised to cause cavernous sinus thrombosis were studied as given in Table 3. Although odds of > 1 were seen in some, none of the factors analysed was statistically significant.

In COVID-19 patients with mucormycosis, the odds of dying were 3.2 when compared to those without COVID-19 (Table 4). The odds of death in CST were 0.9 compared to those without CST in mucormycosis irrespective of COVID-19 status. In a COVID-19 positive patient with mucormycosis, the odds of dying with CST was one. However, all the odds calculated were not statistically significant.

\section{Discussion}

The incidence of mucormycosis rose significantly during the COVID-19 pandemic. In the current study, $67.2 \%$ of the patients with mucormycosis were not COVID-19 positive during the first wave. In the remaining, COVID-19 infection occurred as an incidental diagnosis in patients who were otherwise predisposed to develop mucormycosis and could probably be attributed to the rapid phase of the pandemic in the first wave. It is essential that this chance finding of COVID-19 in a mucor patient be considered separately from the other CAM cases. COVID-19 occurring after or concurrently with mucormycosis cannot cause mucormycosis and is unlikely to be a predisposing factor and could have been an association due to the high incidence of COVID-19 in the population presenting to the hospital. Patients with incidentally detected COVID-19 simultaneously as mucormycosis as seen in this study were not previously treated with steroids or oxygen therapy; hence the association was probably unrelated [5] to the treatment for COVID-19. Studies published recently regarding COVID-19 literature in the first wave [6] [7] have given data only on CAM, but not the non-COVID-19 mucormycosis or even incidental COVID-19 detected in a mucormycosis patient, the numbers of which have risen sharply as well. Many non-COVID19 positive mucormycosis patients were also treated at the study centre in the first wave over 20202021 , compared to the numbers of mucormycosis seen in previous years. The role of other unknown factors must be looked into for this rise of mucormycosis in both COVID-19 positive and negative patients. Data might be available in the future when institutions start reporting mucormycosis in the second wave, without associated COVID-19.

Infection in the dangerous area of the face may involve the cavernous sinus by retrograde spread through the valveless veins. The association of CST in mucormycosis is a well-known and fatal complication, reported, even before COVID-19 [8]. Invasive mucormycosis can spread contiguously into the cavernous sinus due to anatomical proximity or an infection in the dangerous area of the face. Discrete data on the contiguous spread or embolic phenomena occurring from the danger area of the face in mucormycosis has not been reported even in pre-COVID-19 literature. The current study has attempted to analyse the possible factors involved in the contiguous spread of CST in invasive fungal disease. Thirty-four patients had involvement of the sphenoid sinus, either alone or in combination with other sinuses, whereas only 
$13(=38.2 \%)$ of them had involvement of the cavernous sinus. Simultaneous involvement of the sphenoid sinus and the orbit was $73.7 \%$ of the entire study population. Interestingly in $71.4 \%$ of patients with CST had a similar incidence of sphenoid and orbit involvement. It was found that not all patients of mucormycosis with sphenoid sinus involvement had CST, questioning the role of contiguous spread of the infection from the sphenoid into the cavernous sinus directly, even considering the rapid progression of invasive mucormycosis. Isolated case studies exist [9] [10], suggesting possible spread from adjacent involved paranasal sinuses; however, definitive data on the pathogenesis of CST with mucormycosis needs more research regarding the breach of bony boundaries and mucosal barriers.

In patients of COVID-19 infection with associated severe lung disease, COVID-19 related coagulopathy has been proposed as a risk factor. Thromboembolic manifestations are now considered a biomarker of the disease, with various studies suggesting measures to improve survival outcomes [11] [12]. Increased ACE-2 levels, pro-inflammatory cytokine storms, and complement activation all have been hypothesised for COVID-19 coagulopathy. The presence of novel ACE-2 receptors with tropism for the epithelia of the respiratory tract probably has a role. Patients with severe COVID-19 infection have been seen to develop thrombotic events, including pulmonary embolism, deep vein thrombosis (DVT), arterial thrombosis, and intra-catheter thrombosis. However, data is scarce concerning cavernous sinus thrombosis, primarily due to its low incidence and high mortality, in both the pre-and post-COVID-19 times. A study by Abdelkader et al. investigated CST in COVID-19. Only 3.03\% (one out of 8 patients) had cavernous sinuses involvement [13], where the superior sagittal sinus was the most commonly affected sinus in CSVT.

An important question raised in this study was whether COVID-19 caused this increased incidence of cavernous sinus thrombosis seen in the mucormycosis patients. Although this descriptive data showed 20 COVID-19 positive mucormycosis cases, the proportions calculated are given in Table 3 . Only 5 out of the $20(=25 \%)$ COVID-19 positive patients had CST, with the odds ratio being 0.5 with confidence intervals of 0.1 to 1.7 , with no statistical significance. Though the sample size is small, an inference obtained was that CST might not be attributed to the claimed microangiopathic properties of the COVID-19 virus. The odds of getting CST with orbit or sphenoid or ethmoids being involved with mucormycosis is similarly less than 1, casting doubts about the association of CST in the mucor patients. Hypercoagulable states like low platelet counts and high blood sugars were also associated with low odds ratios, as depicted in Table 3. Further studies are needed to study risk factors for CST and its underlying associations and explore other associations.

Out of the 61 patients with mucormycosis reported in the present series, $15(=25 \%)$ patients succumbed to the disease, due to various reasons, during their stay in the hospital. In the pre-COVID-19 era, the mortality rates reported even by the CDC (Centre for Disease Control, Atlanta) were high, with values ranging from 46-96\% [14], depending on the extent of the disease. Even with aggressive combined medical and surgical treatment, studies have shown a high fatality rate of over 50\% for ROCM [15] [16] [17]. The present study showed a slightly lower mortality rate with the available data, but follow-up for mortality outcomes after leaving the hospital was not undertaken. 
Though the odds of dying in COVID-19 positive patients were 3.23 compared to COVID-19 negative patients, the confidence interval was very wide and not significant. It may be attributed to the relatively small sample size of the present study. The odds of dying in mucormycosis patients was one in patients with simultaneous COVID-19 and CST compared to patients of COVID-19 infection without CST, with a wide confidence interval, but was statistically insignificant. The odds of dying CST alone were 0.93 when compared with mucormycosis patients without CST. More extensive studies are needed to study the causal association of CST with mucormycosis to conclude any significant associations. CST has been associated with mortality, although it has not been studied as an independent predictor of mortality so far in literature [18] [19].

\section{Strengths of the study}

This study attempts to correlate factors causing CST and mortality, in patients of invasive mucormycosis, both with and without COVID-19. This knowledge will help improve outcomes, especially in CAM patients, and stresses the need for timely management of CST. This is the first study that looked into the association between CST and CAM to the best of our knowledge.

\section{Limitations of the study}

This was a retrospective records-based study, where the diagnosis of CST was made from CT scans. Clinical features of CST in the study subjects were not considered. The study had a relatively short followup period till the discharge of the patient from the hospital. This study does not suggest etiopathogenesis of CST in mucormycosis but looked into potential factors associated with CST.

\section{Conclusion}

$34.4 \%$ of patients with mucormycosis developed CST. The was no increased risk of developing CST in COVID-19 co-infection. During the first wave of COVID-19, this study observed that $67.2 \%$ of the cases of mucormycosis were COVID-19 negative. However, being COVID-19 positive led to an increased chance of mortality. The survival rates in invasive mucormycosis did not drop significantly in CST patients with COVID-19 co-infection. Further studies are needed to shed light on the pathogenesis of CST in mucormycosis, both in the COVID-19 and non-COVID-19 patients.

\section{Declarations}

Funding: This study did not receive any funding from government or not-for-profit sectors

Conflicts of interest/Competing interests: The authors have no conflict of interest/ competing interests to declare.

Availability of data and material: Yes

Code availability: N.A 
Authors' contributions All authors contributed to the study conception and design. Material preparation, data collection and analysis were performed by [Stuti Chowdhary], [Arun Alexander] and [Sivaraman Ganesan]. The first draft of the manuscript was written by [Stuti Chowdhary] and all authors commented on previous versions of the manuscript. All authors read and approved the final manuscript.

Ethics approval: Approval from the institute ethics committee was obtained (No. JIP/IEC/2021/084)

Consent to participate: N.A

Consent for publication: N.A

\section{References}

1. Hameed S, Wasay M, Soomro BA, Mansour O et al. Cerebral Venous Thrombosis Associated with COVID-19 Infection: An Observational, Multicenter Study. Cerebrovasc Dis Extra. 2021 May 11;11(2):55-60. DOI: 10.1159/000516641. Epub ahead of print. PMID: 33975306; PMCID: PMC8215987

2. Bhansali A, Bhadada S, Sharma A, Suresh V, Gupta A, Singh P et al. Presentation and outcome of rhino-orbital-cerebral mucormycosis in patients with diabetes. Postgrad Med J. 2004 Nov;80(949):670-4. DOI: 10.1136/pgmj.2003.016030. PMID: 15537854; PMCID: PMC1743145.

3. Khacha A, Bouchal S, Ettabyaoui A, Haloua M, Lamrani YA, Boubbou M et al. Cavernous sinus thrombosis in a COVID-19 patient: A case report. Radiol Case Rep. 2021 Mar;16(3):480-482. doi: 10.1016/j.radcr.2020.12.013. Epub 2020 Dec 9. PMID: 33318774; PMCID: PMC7723769.

4. Mehta S, Pandey A. Rhino-Orbital Mucormycosis Associated With COVID-19. Cureus. 2020 Sep 30;12(9):e10726. DOI: 10.7759/cureus.10726. PMID: 33145132; PMCID: PMC7599039.

5. Singh AK, Singh R, Joshi SR, Misra A. Mucormycosis in COVID-19: A systematic review of cases reported worldwide and in India. Diabetes Metab Syndr. 2021 May 21;15(4):102146. DOI: 10.1016/j.dsx.2021.05.019. Epub ahead of print. PMID: 34192610; PMCID: PMC8137376.

6. Sen M, Honavar SG, Bansal R, Sengupta S, Rao R, Kim U, et al., members of the Collaborative OPAIIJO Study on Mucormycosis in COVID-19 (COSMIC) Study Group. Epidemiology, clinical profile, management, and outcome of COVID-19-associated rhino-orbital-cerebral mucormycosis in 2826 patients in India - Collaborative OPAI-IJO Study on Mucormycosis in COVID-19 (COSMIC), Report 1. Indian J Ophthalmol. 2021 Jul;69(7):1670-1692. DOI: 10.4103/ijo.IJO_1565_21. PMID: 34156034.

7. Garg D, Muthu V, Sehgal IS, Ramachandran R, Kaur H, Bhalla A et al. Coronavirus Disease (Covid-19) Associated Mucormycosis (CAM): Case Report and Systematic Review of Literature.

Mycopathologia. 2021 May;186(2):289-298. DOI: 10.1007/s11046-021-00528-2. Epub 2021 Feb 5. PMID: 33544266; PMCID: PMC7862973.

8. Kristoffersen ES, Harper CE, Vetvik KG, Faiz KW. Cerebral venous thrombosis - epidemiology, diagnosis and treatment. Tidsskr Nor Laegeforen. 2018 Aug 20;138(12). English, Norwegian. DOI: 10.4045/tidsskr.17.1047. PMID: 30132621. 
9. Haber DM, Fernandes AM, Neto DDS, Schiavetto RR. Rhino-orbitocerebral Mucormycosis Associated with Cavernous Sinus Thrombosis: Case Report. Int. Arch. Otorhinolaryngol. 2008; 12(4): 574-578.

10. Dolapsakis C, Kranidioti E, Katsila S, Samarkos M. Cavernous sinus thrombosis due to ipsilateral sphenoid sinusitis. BMJ Case Rep. 2019 Jan 29;12(1):e227302. DOI: 10.1136/bcr-2018-227302. PMID: 30700458; PMCID: PMC6352844.

11. Al-Samkari H, Karp Leaf RS, Dzik WH, Carlson JCT et al. COVID-19 and coagulation: bleeding and thrombotic manifestations of SARS-CoV-2 infection. Blood. 2020 Jul 23;136(4):489-500. DOI: 10.1182/blood.2020006520. PMID: 32492712; PMCID: PMC7378457.

12. Iba T, Levy JH, Connors JM, Warkentin TE, Thachil J et al. The unique characteristics of COVID-19 coagulopathy. Crit Care. 2020 Jun 18;24(1):360. DOI: 10.1186/s13054-020-03077-0. PMID: 32552865; PMCID: PMC7301352.

13. Abdalkader M, Shaikh SP, Siegler JE, Cervantes-Arslanian AM et al. Cerebral Venous Sinus Thrombosis in COVID-19 Patients: A Multicenter Study and Review of Literature. J Stroke Cerebrovasc Dis. 2021 Jun;30(6):105733. DOI: 10.1016/j.jstrokecerebrovasdis.2021.105733. Epub 2021 Mar 4. PMID: 33743411; PMCID: PMC7931726.

14. Mucormycosis Statistics | Mucormycosis | Fungal Diseases | CDC. 2020 [Accessed 2021 Jun 28]. Available from: https://www.cdc.gov/fungal/diseases/mucormycosis/statistics.html

15. Patel A, Kaur H, Xess I, Michael JS et al. A multicentre observational study on the epidemiology, risk factors, management and outcomes of mucormycosis in India. Clin Microbiol Infect. 2020 Jul;26(7):944.e9-944.e15. DOI: 10.1016/j.cmi.2019.11.021. Epub 2019 Dec 4. PMID: 31811914.

16. Jayalakshmi SS, Reddy RG, Borgohain R et al. Predictors of mortality in rhinocerebral mycosis. Neurol India. 2007 Jul-Sep;55(3):292-7. DOI: 10.4103/0028-3886.35692. PMID: 17921660.

17. Chakrabarti A, Singh R. Mucormycosis in India: unique features. Mycoses. 2014 Dec;57 Suppl 3:8590. DOI: 10.1111/myc.12243. Epub 2014 Sep 3. PMID: 25187095.

18. Hong HL, Lee YM, Kim T, Lee JY et al. Risk factors for mortality in patients with invasive mucormycosis. Infect Chemother. 2013 Sep;45(3):292-8. DOI: 10.3947/ic.2013.45.3.292. Epub 2013 Sep 27. PMID: 24396630; PMCID: PMC3848522.

19. Spellberg B, Kontoyiannis DP, Fredricks D, et al. Risk factors for mortality in patients with mucormycosis. Med Mycol. 2012;50(6):611-618. doi:10.3109/13693786.2012.669502.

\section{Tables}

Table: 1 Demographic character and clinical course of mucormycosis patients. 


\begin{tabular}{|c|c|c|}
\hline & $\begin{array}{c}\text { COVID-19 } \\
\text { positive }(n=20)\end{array}$ & $\begin{array}{c}\text { COVID-19 } \\
\text { negative }(\mathrm{n}=41)\end{array}$ \\
\hline Mean age, years (SD) & $50.8 \pm 13.1$ & $49.4 \pm 9.6$ \\
\hline \multicolumn{3}{|l|}{ Gender } \\
\hline Male & 15 & 29 \\
\hline Female & 5 & 12 \\
\hline \multicolumn{3}{|l|}{ Underlying comorbidities } \\
\hline None & 0 & 2 \\
\hline Diabetes mellitus & 20 & 37 \\
\hline Systemic Hypertension & 2 & 5 \\
\hline Kidney Disease & 5 & 10 \\
\hline Others & 3 & 3 \\
\hline \multicolumn{3}{|c|}{ Vision at presentation of mucormycosis (Snellen's) $(\mathrm{n}=61)$} \\
\hline Normal $(6 / 6)$ & 1 & 6 \\
\hline Diminished vision (6/9 to $6 / 60$ ) & 7 & 23 \\
\hline Hand movements & 1 & 3 \\
\hline No perception of light & 11 & 9 \\
\hline \multicolumn{3}{|c|}{ Blood glucose at presentation of mucormycosis $(\mathrm{mg} / \mathrm{dL})(\mathrm{n}=61)$} \\
\hline$<140$ & 2 & 11 \\
\hline $140-300$ & 8 & 20 \\
\hline$>300$ & 10 & 10 \\
\hline \multicolumn{3}{|c|}{ Radiological cavernous sinus thrombosis $(n=21)$} \\
\hline Partial & 2 & 7 \\
\hline Diffuse & 3 & 9 \\
\hline No cavernous sinus thrombosis & 15 & 25 \\
\hline \multicolumn{3}{|l|}{ Medical management } \\
\hline $\begin{array}{l}\text { Liposomal /conventional } \\
\text { amphotericin B }\end{array}$ & 18 & 36 \\
\hline Surgical management & 12 & 37 \\
\hline Endoscopic & 3 & 20 \\
\hline Open & 5 & 7 \\
\hline Combined endoscopic + Open & 1 & 8 \\
\hline Orbital exenteration & 3 & 2 \\
\hline Died before surgery & 6 & 3 \\
\hline Refused surgical treatment & 2 & 1 \\
\hline \multicolumn{3}{|l|}{ Outcome } \\
\hline Died & 8 & 7 \\
\hline Survived & 12 & 34 \\
\hline
\end{tabular}


Total dose of Amphotericin received (mg) ( $\mathrm{n}=54)$

\begin{tabular}{|l|c|c|}
\hline$<2000$ & 4 & 9 \\
\hline $2000-2500$ & 8 & 22 \\
\hline$>2500$ & 6 & 5 \\
\hline
\end{tabular}

Table 2: Extent of disease in mucormycosis using CT scan.

\begin{tabular}{|c|c|c|c|}
\hline Radiological evidence of disease & $\begin{array}{c}\text { Number of patients }(\mathbf{n}= \\
\mathbf{6 1 )}\end{array}$ & $\begin{array}{c}\text { CST } \\
\text { present } \\
(\mathbf{n}=\mathbf{2 1})\end{array}$ & $\begin{array}{c}\text { COVID-19 } \\
\text { positive } \\
\text { (n= 20) }\end{array}$ \\
\hline Maxillary sinus & 54 & 19 & 18 \\
\hline Ethmoid sinuses & 56 & 19 & 19 \\
\hline Sphenoid sinus & 34 & 13 & 15 \\
\hline Frontal sinus & 13 & 4 & 3 \\
\hline Pterygopalatine fossa & 11 & 4 & 2 \\
\hline Orbit & 32 & 11 & 13 \\
\hline Sphenoid sinus and orbit & 21 & 9 & 10 \\
\hline simultaneous & & & \\
\hline
\end{tabular}

Table 3: Hypercoagulable conditions associated with cavernous sinus thrombosis 


\begin{tabular}{|c|c|c|c|}
\hline Laboratory parameters & $\begin{array}{c}\text { CST } \\
\text { present } \\
(n=21)\end{array}$ & $\begin{array}{c}\text { CST } \\
\text { negative } \\
(n=40)\end{array}$ & $\begin{array}{l}\text { Odds ratio with Confidence } \\
\text { interval }\end{array}$ \\
\hline \multicolumn{4}{|l|}{ COVID-19 status } \\
\hline COVID-19 positive $(n=20)$ & 5 & 15 & \multirow[t]{2}{*}{$0.5(0.1-1.7)$} \\
\hline $\begin{array}{l}\text { COVID-19 negative }(n= \\
\text { 41) }\end{array}$ & 16 & 25 & \\
\hline \multicolumn{4}{|c|}{ Platelet counts at presentation (per $\mu \mathrm{L}$ ) } \\
\hline$>4,50,000$ & 3 & 7 & \multirow[t]{2}{*}{$0.8(0.2-3.4)$} \\
\hline$<4,50,000$ & 18 & 33 & \\
\hline \multicolumn{4}{|c|}{ Random blood glucose at presentation (mg/dL) } \\
\hline$>300$ & 7 & 13 & \multirow[t]{2}{*}{$1.03(0.3-3.2)$} \\
\hline$<300$ & 14 & 27 & \\
\hline
\end{tabular}

Table 4: Mortality outcomes in patients with cavernous sinus thrombosis and COVID-19

\begin{tabular}{|c|c|c|c|}
\hline Attributes & $\begin{array}{l}\text { Death } \\
(n=15)\end{array}$ & $\begin{array}{c}\text { Survival } \\
(\mathrm{n}=46)\end{array}$ & Odds ratio with Confidence Interval \\
\hline \multicolumn{4}{|l|}{ COVID-19 status } \\
\hline COVID-19 positive & 8 & 12 & \multirow{2}{*}{$3.2(0.1-10.9)$} \\
\hline COVID-19 negative & 7 & 34 & \\
\hline \multicolumn{4}{|l|}{ CST status } \\
\hline Cavernous sinus thrombosis +ve. & 5 & 16 & \multirow{2}{*}{$0.9(0.3-3.2)$} \\
\hline Cavernous sinus thrombosis -ve. & 10 & 30 & \\
\hline \multicolumn{4}{|l|}{ Concurrent COVID-19 and CST } \\
\hline COVID-19+ and CST + & 2 & 3 & \multirow[b]{2}{*}{$1(0.1-7.8)$} \\
\hline COVID-19 + and CST - & 6 & 9 & \\
\hline
\end{tabular}

\section{Figures}




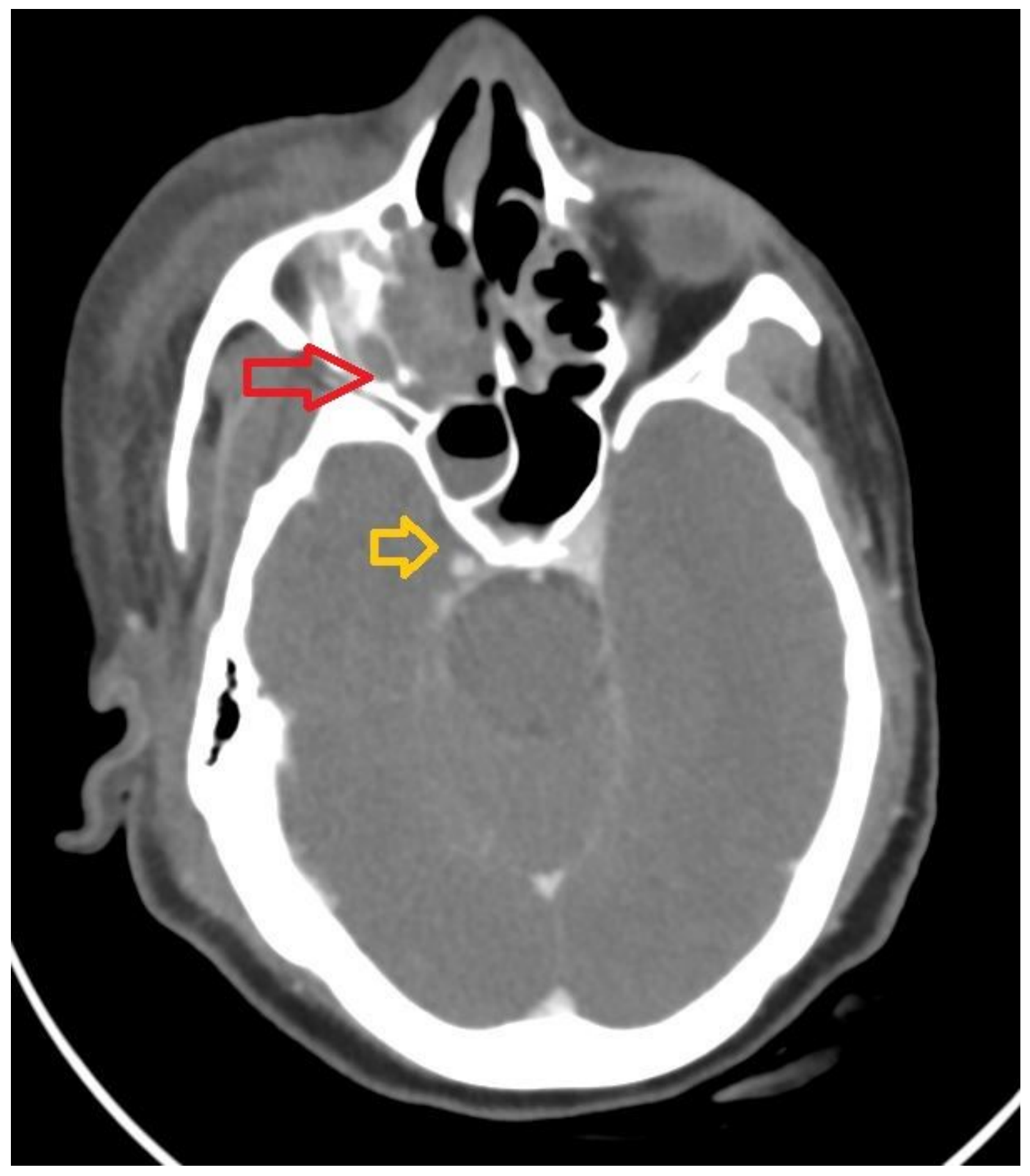

Figure 1

CT scan of the Orbit and Paranasal sinuses showing disease in the right ethmoids and orbit (red arrow) and absence of intravenous contrast in the right cavernous sinus (yellow arrow) 


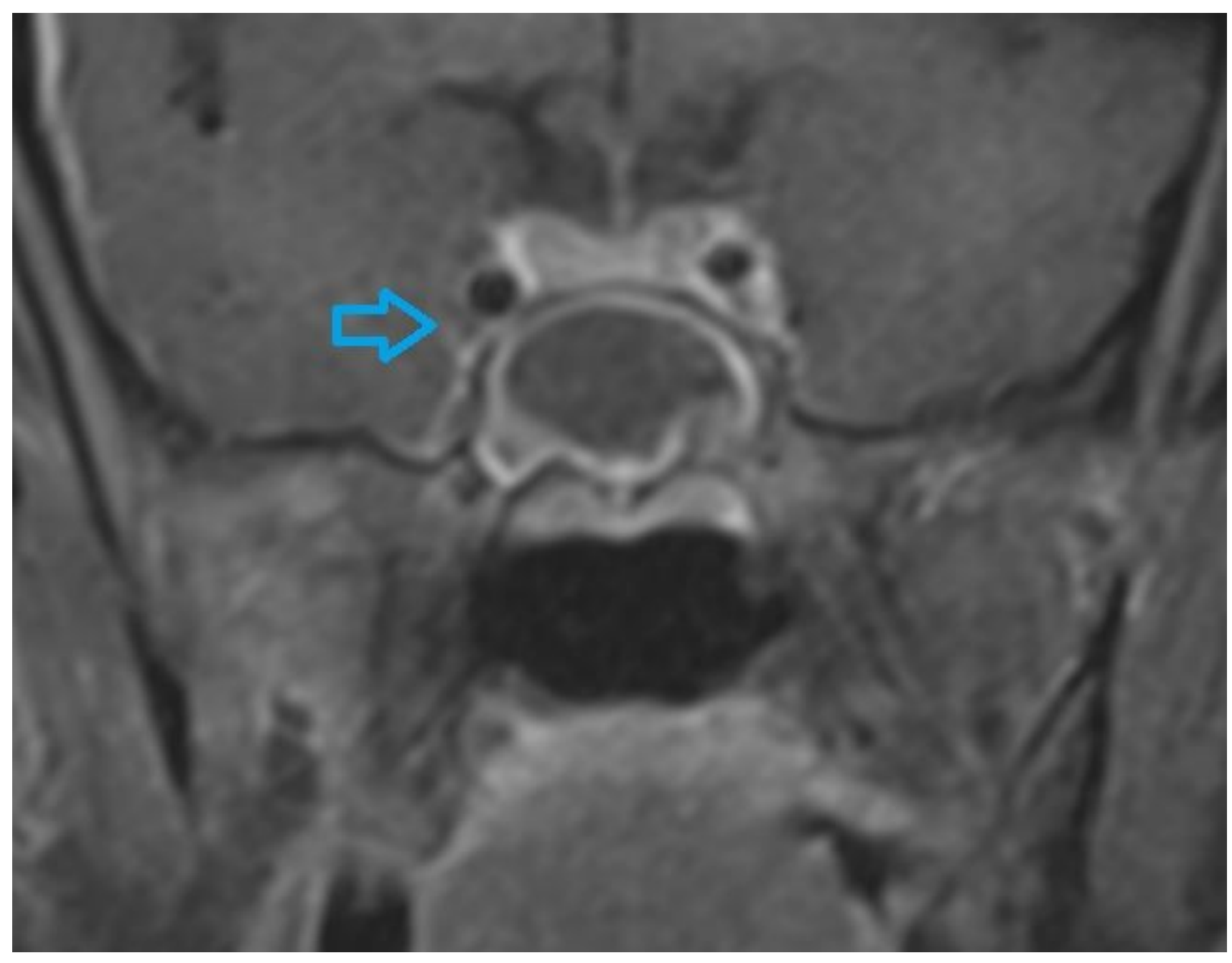

\section{Figure 2}

MRI of the brain T1 weighted coronal section showing incomplete filling of the right cavernous sinus suggesting a cavernous sinus thrombosis (blue arrow) 